\title{
SOTIP as a Model for Outsourcing of Telecom Services for the Public Sector
}

\author{
Helena Lindskog \\ Department of Management and Economics \\ Linköping University \\ helli@eki.liu.se
}

\begin{abstract}
The political intentions for the past 20 years have broadly speaking been to reduce the number of publicly owned and publicly run activities. Outsourcing is an often applied way to cut public spending by totally or partially privatize public activities. Telecommunications is an obvious outsourcing candidate as it is hardly a core activity for the public sector. Furthermore, there is today a competitive market for telecommunications services.

At the same time it can be difficult to separate telecommunications from other activities as every organization's processes and virtually all employees use telecommunications services.

Sweden was one of the first countries in the world to introduce full competition on the telecom market and exposed to the new ways to procure and outsource telecom services. A SOTIP (Swedish government Open Telecommunications systems Interconnection Profile) model for procurement of telecommunications services outgoing from users' needs was developed in order to meet these new requirements. A buyer or outsourcer can use SOTIP as a checklist in order to avoid mistakes by forgetting some important requirements.

Key words: outsourcing, public procurement, telecommunications, procurement model

\section{Background}

For more than one hundred years telecommunications has been treated as a commodity provided by the government monopoly. Telecommunications was necessary but without any choices of service delivery. In Sweden, PABXs (Private Automatic Branch Exchange) or even telephones were still some 25 years ago owned by the Swedish monopolist, the operator Televerket. Sweden was not unique in this respect. Almost all countries in the world had this kind of arrangement. The first parts of the telecommunications' market to be liberated were PABXs (in the beginning of the 1980s) and many organizations could begin to purchase PABXs on a new more competitive market.
\end{abstract}

The introduction of competition on the telecommunications market is one of the most dramatic and rapid economic changes that have taken place. The explosive technical development with e.g. Internet, wireless and broadband coincided with the demonopolization of the telecommunications market. Competition gives rise to many advantages to the users with choices of different service providers, ranges of functions and services, pricing and billing schemes, increased equipment assortment and contract types. The competitive market dynamics have also introduced a rapid development of many new services in order to differentiate different players' market offers. With the steadily growing importance of telecommunications in all aspects of our life, to choose telecom solution has not only technical consequences but also economical. These consequences can be difficult to foresee even for technically skilled people.

The political intentions for the past 20 years have broadly speaking been to reduce the number of publicly owned and publicly run activities. Outsourcing is an often applied way to cut public spending by totally or partially privatize public activities. Telecommunication is an obvious outsourcing candidate as it is hardly a core activity for the public sector. Furthermore, there is today a competitive market for telecommunications services.

For many years in Sweden the only way to obtain competition and some independence from the monopolist operator was to buy equipment such as PABXs, to build own telecom networks and to hire staff to run telecom services. This situation changed dramatically with the introduction of competition on telecom market some 6-8 years ago. At that time most of the authorities had their own telecom networks. Tradition of buying telecom services in competition was non-existent and the pay-off time for PABXs was 10-15 years.

In order to take full advantage of this new market situation the management of many authorities considered buying services instead for buying equipment and managing own staff. As a result of these considerations the question of structuring requirements on telecom services outgoing from users' needs was raised. A special commission for procurement of telecom services was 
established and one of the first tasks was to investigate if there existed any models suitable to use for this purpose. But since a liberated telecom market was a novelty, there were no telecom models available. Hence, the commission decided to develop such a model. Afterwards the SOTIP model was adopted by the European Commission and as EOTIP (European Open Telecommunication systems Interconnection Profile) it is still recommended to the member states.

\section{Purpose of the article}

The purpose of this article is to investigate the relevance of SOTIP for outsourcing of telecom services in the public sector.

\section{Definition of outsourcing}

It is difficult to find an all-exclusive definition of outsourcing. Definitions span from almost any type of purchasing through make-or-buy decision to takeover of a function from one organization to another. For the purpose of this paper outsourcing is defined as a one-time event for a specific function that previously has been a part of an organization and afterwards becomes a part of another organization and the relation between these organizations is regulated by a contract.

\section{Procurement, make-or-buy decision and outsourcing}

Outsourcing is a result of a decision to discontinue to "make" a specific function in-house. This change from internal to external provision of a functional activity makes the outsourcing decisions strategic in nature and they are likely to have a great impact on the organization. In addition, outsourcing decisions are many times more or less irreversible since they involve a takeover of personal and physical assets.

There can be several quite different reasons for outsourcing, both rational and less "rational" ones. Rational decision based on actual costs, core competence and market situation can nevertheless give rise to positive or negative consequences, which are difficult to predict.

Outsourcing of activities that were traditionally provided by the buyer's organization has grown considerably over the years. [2] Frequent explanations include:

- Stage of purchasing development reached is not sufficient to give the organization the competitive advantage required. Outsourcing the activity to a more advanced strategically proactive organization.

- $\quad$ The existing organization structure cannot deal with rapid change.
- Existing structures and procedures make efficient/effective buying strategies impossible e.g. the public sector. In such cases outsourcing the purchasing activity to the private sector might give considerable gains. [2]

Peter Kraljic (1983) developed one of the most influential and by now classical approaches to this problem in the form of a 2:2 matrix. See figure 1. The first functions that should be considered for outsourcing are such that several suppliers can provide the functions and when the function itself is not of strategic value for the organization. In general, functions that are candidates for outsourcing or make-or-buy decisions should be analyzed starting from their potential risks, profit potential and strategic value for the organization.

Figure 1. The "Procurement Positioning" tool

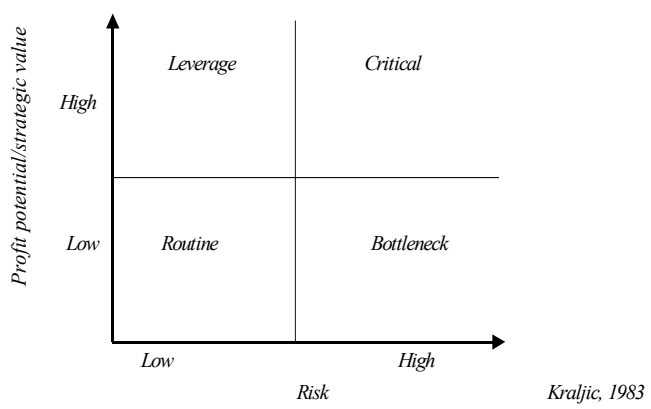

Following Kraljic (1983) analysis, outsourcing is essentially the contracting out of non-core activities on a competitive supplier market. Outsourcing is not synonymous with procurement or purchasing.

The outsourcing decisions should not be taken on the operational level, but involve top management. Type of questions to be considered before starting any of outsourcing activities:

- Do we have candidate functions for outsourcing?

- How do we select?

- How do we assess ourselves?

- Who are the potential providers?

- How do we assess them?

- What sort of relationship will we form?

- How will we manage it?

- How do we ensure efficiency?

Outsourced functions normally lead to relationships where the vendor is providing services on a continuous basis. [2] 


\section{Theoretical overview}

There are three main theoretical approaches to the phenomenon of outsourcing:

- Core competence

- Network

- Transaction cost

In addition, a general model of outsourcing will be discussed.

\subsection{Core competence}

Prahalad and Hamel suggested that companies need to understand fully their core competencies and capabilities in order to successfully exploit their resources.

They define these terms as a combination of production skills and technologies. [10]

To concentrate the organization's activities on core competencies can be a motive for outsourcing of noncompetence activities.

Contrary to what Hancox, Martin \& Hachney, Ray (2000) say that there may be particular uncertainty about what is core in the public sector, I would suggest that the core competence discussion is sometimes easier to have in the public sector environment. The reason is that all truly core competencies in the public sector are imposed by the constitution or other base laws and cannot be outsourced. Examples are various authorities, audit, control, legislation, protection of civil rights etc. However, what is or is not an authority or belonging to the public sector's responsibility in general varies from country to country and from time to time.

For many years and in most countries the infrastructures such as electricity, railways, waterways or telecommunications have been considered as belonging to the government responsibility. These functions are many times today totally de-monopolized and provided by several competing private companies. The authorityfunction is a minor part typically carried out by special regulatory authorities.

Activities such as education, nurseries or healthcare are in different countries considered to belong only to public, only to private or a combination of both public and private providers. There are regulatory and controlling functions that "naturally" belong to the public sector, but typically many activities and services can be produced in both private enterprises and public owned organizations. It is within this area where outsourcing is typically taking place. However, quite often the decisions to do so have been based more on belief than reality.

Sweden is an example where many services used to be produced almost solely in the public sector and outsourcing of them to the private sector was forbidden. Public monopolies existed in many areas. However, even in such a market there always exist parts of every service production that could either be bought from an external service provider or produced in-house. Typical examples are IT, telecom, cleaning, washing etc.

\subsection{Network Theory}

A network is generally defined as a specific type of relation linking a defined set of persons, objects, or events. Different types of relations identify different networks, even when imposed on an identical set of elements.

The set of persons, groups, organizations, objects or events on which a network is defined may be called the actors or nodes. The actors or nodes are connected by a set of ties. A network analysis takes into account both the relations that occur and those that do not exist among the actors. The relations among actors have both content and form.

The Network theory approach is less relevant for public procurements including outsourcing since the public sector is highly formalized and all contacts with actual and potential suppliers should be on an arm-length distance.

\subsection{Transaction cost theory}

Transaction cost theory (TCT), introduced by Coase (1937) and developed principally by Williamson (1975, 1979, 1981, 1985), maintains that the organization of economic activity depends on balancing production economics, such as scale, against the cost of transacting. Transactions are here the exchanges of goods or services between economic actors, who are technologically separate units, inside and/or outside the organization (Williamson, 1981) [4]

This theory also provides an excellent framework for analyzing the outsourcing option, since the essential choice here is between using an outsourcing service provider (a market mechanism) and providing in-house services (an organizational hierarchy) [4]

Transaction cost drivers can increase transaction costs as a result of human behavior and transaction dimensions. Behind human behavior can be seen bounded rationality or opportunism. Transaction dimensions that can increase a transaction cost are:

- asset specificity or degree to which the transaction will produce an asset that is dedicated to a special purpose with poor alternative to uses

- the degree of uncertainty in the environment as it impacts the contract and its fulfillment

- infrequency of contracting, or the infrequency with which the two parties contract together (Williamson, 1985) [4] 
The total cost consists of production costs, governance costs such as bureaucratic costs and incentive losses and transaction costs both before and after the takeover of the specific function.

For the public sector in general the human behavior factor is less important as all procurement activities are highly regulated and controlled. Incorrectly handled procurements and any sign of discriminatory treatment can lead to claims for damages in juridical processes. Some times political decisions taken at a central level and imposed on local levels can act as a cost-driver. That happens when central decision-makers are unable or unwilling to take into consideration specific activities or special situations of an authority or public organization.

Often, assets can be quite specific in the public sector due to Organizational culture, the demands of democratic accountability and legislative requirements all imposed on the sampled local authorities transaction costs which could be substantially higher than in the private sector. [9] Many public sector organizations and local authorities, in particular, are doubtful about the degree to which vendors understood the "business" of local government. [9]

It is particularly difficult to calculate and distinguish governance costs as...the public sector contract creation and monitoring are more difficult because of the sector's complexity and because there are costs associated with bureaucracy and democracy which are hard to allocate to specific functions. [9]

In general, there are high "ex ante" transaction costs for the public sector as the whole process of procurement and outsourcing in particular is based on strict rules. A successful outsourcing should considerably reduce the "ex post" transaction costs.

\subsection{A general outsourcing model}

Ulli Arnold (2000) proposed a general outsourcing model that consists of four major elements:

- outsourcing subject

- outsourcing object

- outsourcing partner

- outsourcing design.

Outsourcing subject is the economic institution, which plans to outsource (or not). The subject has to make the strategic outsourcing decision. Outsourcing objects are processes or process results, which might be outsourced (Reichmann and Polloks, 1995). With regard to the activities of a company we distinguish between:

- the company core (all activities which are necessarily connected with a company's existence

- core-close activities (directly linked with core activities)

- $\quad$ core-distinct activities (supporting activities)

- disposable activities (activities with general availability).
From an industrial perspective, the outsourcing object is closely linked with the degree of manufacturing penetration. Outsourcing partners are all possible suppliers for the activities considered for outsourcing. In this case, supplier is a term in a wider sense. This supplier could also be an in-house supplier, e.g. an independent business unit within a group of firms. [1]

The outsourcing design can be a formal co-working, co-working without formal agreement or spot transactions.

\section{The Public sector and differences between public and private sectors}

The public sector makes up a big portion in any country. The separate organizations within the public sector range from one person to several thousands of employees. They cover such disparate functions and responsibilities as care of the elderly or children, defense and tax collection. Public organizations can be very local as kindergartens or with the responsibility to cover the whole nation as ministries. In most countries the public administration has three levels: central or federal government, regional and local governments. The responsibilities at each level and what is or is not a public domain vary from country to country. However, there seems to be more similarities than differences between different countries' public organization due to similar responsibilities, working areas and citizens' needs.

Possibly, the most profound difference between the private and public sectors regards competition. The lack of competition within the public sector is many times seen as a major problem. However, there are also advantages. They include the possibility for openness and exchange of information, which are unprecedented in the private sector. Furthermore this exchange of experiences between different public organizations does not stop at the border.

The driving force for the development of the public sector is to provide the best possible service at the lowest possible price.

The public sector typically has many contacts with citizens, companies and other organizations. Some public organizations count all citizens, households or enterprises as their "customers". It is quite normal as a citizen to have contacts with at least a dozen public organizations in a year's time. These contacts can be daily, weekly, monthly, quarterly, yearly or more infrequent depending on the question and situation. Enterprises have several obligations towards the public sector. The result is another flow of contacts some regular and some more sporadic.

The public sector delivers services to citizens and enterprises. These services typically involve direct contacts with people e.g. kindergartens, hospitals, police or courts as well as indirect by means of communication 
with citizens, enterprises and other public organizations. The production of almost all goods has been and still is dominated by private companies.

The number of customers to and their contacts with the public sector exceed by a large amount the corresponding numbers for private companies. Only big banks and insurance companies may get close. Every citizen and every company have several different contactentrances to the public sector organizations.

Table 1: Comparison between public and private sectors characteristics. [17]

Competition

Size of organizations

Geographical dispersion

- Local

- Regional

- National

- International

Production

- Goods

- Services

Profit driven

Openness

Contacts with customers

$\begin{array}{lc}\begin{array}{l}\text { Private } \\ \text { yes } \\ 1-10.000+\end{array} & \begin{array}{l}\text { Public } \\ \text { no } \\ 1-10.000+ \\ \text { yes }\end{array} \\ \text { yes } & \text { yes } \\ \text { yes } & \text { yes } \\ \text { yes } & \text { yes } \\ & \text { yes (few) } \\ \text { yes } & \text { no } \\ \text { yes } & \text { yes } \\ \text { yes } & \text { no } \\ \text { no (limited) } & \text { yes } \\ \text { vary } & \text { many }\end{array}$

Public sector goals

The public sector is distinguished from the private sector by the fact that making profit and maximizing shareholders value is not the main objective of public sector organizations, and that the continuity of public sector organization does not depend upon outperforming competitors. [6]

The existence and continuity of most public sector organizations is however not self-evident.... Public sector organizations therefore also face a strong pressure to minimize their costs and to maximize the quality of their services. [6]

...,public sector organizations have to meet demands that most private corporations do not face. Public administration involves political and legal factors that have a value-laden component. Public bodies have as an objective the performance of a socially desirable function, which is not a means to generate income, but an end in itself. A citizen's legal security and equality of rights must be guaranteed. [6]

Most processes in the public sector are unique. However, they are often performed repetitively by a number of similar public sector organizations. Examples include that all municipalities provide social security benefits, all hospitals have similar information needs, as do schools and environmental inspection units. Secondary processes, such as human resources management and bookkeeping, are similar across ministries, provinces and municipalities.

Different processes sometimes need similar information: municipal social security departments and land registry departments both need information on inhabitants. Many public sector organizations could therefore benefit from using the same information systems or achieve considerable economies of scale. Cooperation ca be more easily achieved in the public sector than in the private sector, as public sector organizations do not compete. [6]

\section{Public procurement}

The public sector is the biggest single buyer in any country. It is buying standard goods, complicated equipment, services ranging from cleaning offices to management consulting or mobile telephony, medicines, building of bridges or digging of tunnels and so on.

Total public procurement in the EU - i.e. the purchases of goods, services and public works by governments and public utilities - is estimated at about $16 \%$ of the Union's GDP or $€ 1500$ billion in 2002. Its importance varies significantly between Member States ranging between $11 \%$ and $20 \%$ of GDP. The opening up of public procurement within the Internal Market has increased cross-border competition and improved prices paid by public authorities. There remains potential for significant further competition in procurement markets and for further savings for taxpayers. [3]

In many cases private companies consider selling to the public sector more tedious, risky and costly than selling to other private companies. They find it difficult to be sure of getting any contracts and profitability is not always ensured. These circumstances make it difficult and almost impossible for small or medium sized enterprises to prepare tenders, especially as there are almost as many ways to prepare "Requests for proposals" and specifying their requirements as there are public organizations. In addition, the buyers' competence and knowledge can be limited. Many organizations depend on external consultants and this expertise must also be procured.

Public procurements can have the same goals as private ones. However, public procurements are subject to a different and stricter jurisdiction than private procurements. The purpose is to protect companies from unfair competition and to avoid corruption and bribery. The result is often that the formal requirements become quite extensive and lengthy.

Contacts between buyers and bidders/prospective contract winners must during the procurement process be very limited. This puts high demands on the procuring organization to structure the requirements of the purchased service or equipment as a published "Request for proposal" cannot be changed. Consequently, the seller 
cannot change submitted proposals and only under some special circumstances supplement with additional information.

It is seldom customary for private companies to reveal their needs and detailed requirements by publishing them openly visible for everybody. It is more of choosing from existing lists in buying staple goods or simpler services. For more complex requirements direct contacts can be taken or a request can be published in order to initiate a dialogue with some selected suppliers.

But what mostly characterizes the private market is an active role of sellers that are looking for any opportunities to sell their products or services. Negotiations, changes of terms, prices, requirements, adding extra functionality, reducing the number of licenses etc can be carried out until the last moment of signing a contract. To reveal detailed results such as special terms or prices is not considered to be beneficial to either side.

This makes the public procurement process quite different from the procurement process in the private sector where dialogues and subsequent changes of requirements and proposals are normal procedures. Without understanding and taking into account these differences it can be difficult for private enterprises even to start bidding for governmental contracts.

All European Union countries are obliged to implement the EC procurement directives. Underlying legal basis for the EC procurement directives are contained in the Treaty of Rome, March 1957. The main principles of this Treaty that carry though to the procurement directives aim to:

- Increase transparency of procurement procedures and practices throughout the community

- Allow the free movement of goods, services, capital and people between member states

- Develop effective competition for public contracts

- Standardize specifications

- Provide advance information of procurement needs to the marketplace

The fundamental principles for public procurement in the European Union are:

- Non-discrimination

- Equal treatment

- Transparency

- Proportionality

- Mutual recognition

\section{Telecommunications industry}

The telecommunications industry is an example of a network industry. Economides (2003) lists several features of markets with network effects such as:

- Operators depend on access to each others' network in order to be able to distribute their services
- Initial investments are big for a telecom operator

- After the investment has been done, there are normally no alternative usages for it

- The more users use a network, the better it will work for them

- There are increasing returns to scale of production and the marginal cost is negligible

- There are increasing returns to scale in consumption

- Technical standards are of extreme importance in order to interconnect without high additional development cost, precondition for competition and to avoid "lock in" situations.

- Mobile telephony is a special case as a frequency spectrum is a limited natural resource

- A critical mass is necessary in order to get any benefits from offered services

Network industries constitute a large part of the world economy. Two key network industries are telecommunications providing voice and data service including the Internet and computer software and hardware. Other network industries are e.g. transport (airlines, railroads, roads, ships), news, financial services (clearing houses, ATM networks, credit cards...) and postal services.

Network industries are also important from a public policy point of view as they often provide necessities. Monopolization as well as liberalization of network industries markets has significant social and political implications. In order to achieve fair competition typically requires heavy regulation since market forces alone are not sufficient, social considerations may be in conflict with efficiency and social and private benefits may differ substantially.

\section{Outsourcing and public procurement of telecommunications}

Adopting the general model for outsourcing by Arnold (2000) and applying it for outsourcing of telecommunications especially telephony services yields:

1. The outsourcing subject is a public organization. It may be a local, regional or federal authority. Its leadership is responsible for the decision-making. It can be the director general and her/his staff. It can also be a political entity e.g. at a local level.

2. The outsourcing object is a total or partial provision of the telecommunications function.

3. The outsourcing partners are external suppliers of the telecommunications function.

4. The outsourcing design can be specified through a framework agreement and a contract procured, negotiated and signed on the central level with one or few service providers. The organizations as the outsourcing subjects are authorized to call-off the framework contract totally or partially according to their needs and requirements. 
Adopting the positioning matrix by Kraljic (1983), we can note that the telecommunications market is quite competitive with several operators that can provide a full or partial range of telecommunications services. There are small differences in their ability to provide different services. The operators are more than willing to get a contract. At the same time the strategic value of telecommunications for most of the public organizations is high since the public sector's activities are highly communicative. The service level relies on well functioning telecommunications in order to have contacts with citizens and enterprises as well as externally and internally within the public sector itself.

In summary, the telecommunications function for the public sector should be placed at low risk and high strategic value leading to the quadrant "leverage" in figure 1 .

\subsection{Core competence}

The telecommunications function does seldom belong to the public sector's core competences as it is difficult to classify as an authority, control, legislation, protection of civil rights or law enforcement or the likes, which are imposed by the constitution or other legislation.

There are several functions that can equally be provided by public or private sector and vary from country to country such as health care or kindergartens. These functions were often earlier provided in many countries by the public sector and now are outsourced and put on competition. The decision to expose these activities to competition was a political act and based on a presumption that a private sector is more efficient in providing this kind of services. For the organizations that provide this kind of services it is their very core competence.

This type of outsourcing by public sector organizations to private suppliers is often called privatization. This is more fundamental than outsourcing by private corporations, as it implies transferring activities and resources from the public sector to the private sector. [6]

The privatization trend was based upon implicit ideological assumptions that market solutions are inherently more efficient and that reducing the staffing levels of government organizations would lead to a cheaper and more flexible public sector.

Telecommunications is an internal support function. Other similar functions include electricity, postal service, IT, cleaning, washing, cooking or transports. Traditionally, many of these functions have totally or partially been provided inside the organizations in the same way as in private firms. Today, they are the subject of possible outsourcing or buy-or-make decisions. The issue of what constitutes non-core competence is very relevant and it has been one of the main motives for the outsourcing of these functions.

\subsection{Transaction Costs}

The Swedish governmental commission STATTEL more than 10 years ago carried out one of the biggest investigations on telephony costs. An inquiry was distributed to the Swedish central government authorities. At that time the Swedish government authorities employed approximately 200,000 people excluding military authorities.

The answers represented some 50,000 employees or $25 \%$ of the total number. The results showed that the annual cost of telephony per employee was SEK 6,000. Thus, the cost for all Swedish government authorities was SEK $200,000 \times 6,000=$ SEK 1.2 bn per year. In the beginning of the 1990 s the total Swedish public sector, i.e. central, regional and local excluding military, had more then one million employees. Applying the same cost per employee implies that the total annual cost for public telephony was approximately SEK 6 bn. The assumption for this calculation is that the cost of telephony on average is the same independently of the type of authority.

The analysis of the cost distribution revealed interesting and contra-intuitive findings. The cost distribution:

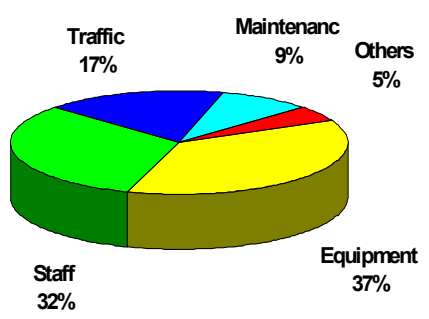

Figure 2 Cost of the telecom for Swedish central government

The most striking result was that the cost of traffic was just $17 \%$. This meant that even if STATTEL could through negotiations procure the traffic for free it would still not be able to reduce the total cost of telephony with the required $25 \%{ }^{1}$. Until this investigation, almost all the efforts done in order to reduce the cost of telephony were focusing on outgoing traffic since the general view stated that the only really important component for the cost of telephony was the outgoing traffic.

The biggest component of the cost was equipment consisting in PBXs (private branch exchange), telephones,

\footnotetext{
${ }^{1} 25 \%$ cost reduction was one of the directives to the Commission.
} 
answering machines and other auxiliaries. The staff includes the internal cost of switchboard operators, administration and technical staff. The ratio between the cost of equipment and service for this equipment was 1:4 and indicated that the service cost was disproportionably high.

The direct reaction of the Commission on the results of this investigation was to initiate an immediate special savings program for better usage of existing equipment and revision of all service contracts, especially on maintenance, before starting any procurement activities. A more profound reaction was to outsource the telecom function to an operator. One of the most important positive effects in this case would be the possibility of control and predictability of telecom cost.

Another way of looking at the telecom cost was to relate them to the overall business costs and how the investments in telecom could be used as a tool for a more efficient public sector, i.e. to achieve a higher service level to the citizens and enterprises at the lowest possible price.

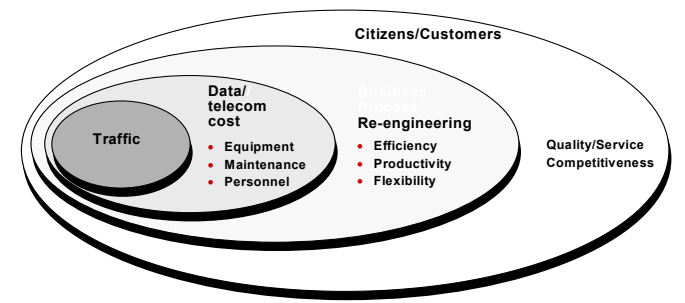

Figure 3. A shift in focus - from cost to business development (Helena Lindskog, 1995)

The benefits that data/telecom can bring to an organization are not always obvious. Traditionally data/telecom has been considered a cost and not as an investment for development. In this Swedish investigation of the telecom cost, it was shown that the cost of traffic stands for approximately only $1 / 5$ of the total telecom cost and the total telecom cost is only a few percent of the overall cost of government agencies. These relations suggest that data/telecom should primarily be used as an efficient tool for reducing the overall cost of business processes, as well as a means for development of better relationships between citizens/customers and the own organizations. This shift of focus is illustrated in figure 3.

The main differences between the private and public sectors are the purpose (profit/non-profit) and financing (shareholders/taxpayers) of main activities. In general data/telecom costs and usage are very similar and can be treated in a similar way independently if they are used in the private or public sectors.
The total cost of telecom excluding IT equipment is often approximately $1.5-3 \%$ of the total business cost. To free 10 minutes of every employee's time per day is more or less equivalent to the total cost of telecommunication.

Outsourcing is considered for many reasons. However, virtually every survey finds the cost reduction is a major objective of the outsourcing process [8]

If cost reduction is a key driver of the outsourcing decision, then accurate cost analysis must precede any correct decision. [8]

Asset specificity for the telecom equipment (mainly PABXs, leased lines and telephones) in general is not high. Only switchboard operators' services can be of high asset specificity.

Centralized call-off types of procurement have low frequency. At the same time there would be several call off local contracts with relatively high frequency dealing mainly with the specific conditions of the contracting authority.

STATTEL encountered high uncertainty as the tasks were of pioneering character. Neither specification nor contract had previously been done. That led to quite high ex ante costs including earlier mentioned investigation of the cost structure, reference group, standardization activities, investigation of future development in telecommunications as well as development of a procurement model SOTIP (Swedish government Open Telecommunications systems Interconnection Profile).

\section{Swedish government Open Telecommunications systems Interconnection Profile $^{2}$ (SOTIP)}

The SOTIP model was formulated during the duration of STATTEL-commission (1991-1996) that had as a main purpose to procure telecommunications for the Swedish public sector. The Government allocated to the commission the task of proposing means to improve the efficiency and service level of telecommunications within the government administration. Agencies were to be offered services encompassing the whole field of telecommunication - telephony, telefax, video, electronic mail etc. - in accordance with the following directives:

- Telephony services, which meet the needs of the agencies in this decade.

- Widely used common telephony services based on standards

- $\quad$ Simplified procedures for provision and operation by procuring services instead of constructing and operating networks

- $\quad$ Procurement with competition when possible

\footnotetext{
${ }^{2}$ Profile is a subset of standards and options chosen for a specific purpose or situation.
} 
- Improved service level to the public, between agencies, and within agencies

- Considerable cost reduction, with a goal of $25 \%$ savings compared to present costs.

The timing for the establishment of STATTEL Commission was strategically chosen in connection with the beginning of the liberalization of the telecommunication market. The Swedish government was committed in getting competition to this market. The establishment of the STATTEL Commission also had political motives to speed up the process of getting competition on the Swedish telecommunication market. By procuring telecommunication services "outsourcing" (data and telephony) in an open for everybody procurement, Sweden could attract foreign investors and operators to establish themselves on the Swedish market. By enacting the Telecommunications Act in 1993 the Swedish telecommunication market became regulated and the rules of competition were established.

In order to take full advantage of the new situation and to empower the users, an idea to create a model for procurement of telecommunication services outgoing from the users' needs was born. This model should give the users maximum possibility to choose without the burden of taking decisions based on detailed technical specifications without obvious connection with an organization's business. The model should also allow procurement of functions in competition and give the decision-makers a better understanding of the organizational and economical consequences of investments in telecom services or equipment.

The motives for developing SOTIP model can be summarized in four points:

- base for specification of requirements on telecom

- standardization

- from technical decisions by technicians to strategic decisions by top-management

- from products to services.

The first version of SOTIP was published in 1995 and consists of four main parts:

Part 0 explains the background, purpose, standardization and importance of telecom for the government administration as well as the future development. In addition, the concept of end-user types is introduced and the classification is described.

Part 1 describes the end-user telecom services for the different end-user types on an individual level.

Part 2 describes the telecom network services for groups of end-users.

Part 3 describes the telecom management services needed for configuration, accounting, security, performance or error detection and recovery for an organization.

The objectives stated in SOTIP are:
- To achieve supplier independent communications based on open system solutions with standardised interfaces between system components,

- To simplify the analysis of user needs, the requirement specification of services and equipment with the aid of a generalised model for describing functional user requirements for telecommunications,

- To create priorities for standardisation process based on a user perspective, and the possibility to influence product development and the competitive situation. [22]

The SOTIP model identifies a number of working situations called end-user types. These end-user types are primarily defined for the Swedish public administration but they are also valid for most other public administrations as well as business organizations. Using this model, the telecommunication needs of each end-user type or group of users are analyzed based upon their role in the business and requirements on telecommunications rather than their position in the hierarchy. The end-users are divided into seven generic types: three as individual end-user types and four as function end-user types.

For each end-user type there is a key functionality. (See a table below).

\begin{tabular}{|c|c|c|c|}
\hline End-user & Type & Description & Key functionality \\
\hline \multirow[t]{3}{*}{ Individual } & PI1 & $\begin{array}{l}\text { Those that } \\
\text { determine their own } \\
\text { availability }\end{array}$ & $\begin{array}{l}\text { Co-ordination } \\
\text { voice and } \\
\text { messaging } \\
\text { Filtering }\end{array}$ \\
\hline & PI2 & $\begin{array}{l}\text { Those that always } \\
\text { must be available. } \\
\text { People on move. }\end{array}$ & Mobile access \\
\hline & PI3 & $\begin{array}{l}\text { Those that not need } \\
\text { to communicate in } \\
\text { their current work }\end{array}$ & $\begin{array}{l}\text { Messaging } \\
\text { Sharing resources }\end{array}$ \\
\hline \multirow[t]{4}{*}{ Function } & PF1 & $\begin{array}{l}\text { Massive incoming } \\
\text { calls handling. Call } \\
\text { centers }\end{array}$ & $\begin{array}{l}\text { ACD (Automatic } \\
\text { Call Distribution) } \\
\text { Co-ordination } \\
\text { voice-data }\end{array}$ \\
\hline & PF2 & $\begin{array}{l}\text { Those that answer, } \\
\text { filter and inform } \\
\text { individual users i.e. } \\
\text { secretaries }\end{array}$ & $\begin{array}{l}\text { Local mobility } \\
\text { The same } \\
\text { information about } \\
\text { individual users } \\
\text { as attendants }\end{array}$ \\
\hline & PF3 & $\begin{array}{l}\text { Massive outgoing } \\
\text { calls handling. } \\
\text { Telemarketing }\end{array}$ & $\begin{array}{l}\text { Co-ordination } \\
\text { voice-data }\end{array}$ \\
\hline & PF4 & $\begin{array}{l}\text { Switchboard } \\
\text { Operator/Attendants }\end{array}$ & $\begin{array}{l}\text { Co-ordination } \\
\text { Voice-data } \\
\text { Service quality } \\
\text { measurements }\end{array}$ \\
\hline
\end{tabular}

Table 2. End-user types and their key functionality. [modified 15]

Additionally, one of the important motives for buying services rather than products was to make it easier for the 
decision-makers to take decisions. It also means a change from procurement of equipment for the internal service provider to procurement of services from an external service provider based on SLA (Service Level Agreement). Independently of the procurement situation, it is important to regulate the interface between internal or external providers and the user organization. It is a must in case of outsourcing or buying telecom services from an external operator.

A part that deals with the management services is especially important in an outsourcing situation when telecom service provision changes from internal and mostly unregulated and external highly formalized and regulated by contract. Management services described in SOTIP can be used as requirements regulating the needs of communication between an organization and its external or internal service provider. Management services are divided into five groups:

- Configuration

- Security

- Performance

- Fault

- Accounting

In the case of outsourcing a buyer can simply follow all checklists and in this way avoid making mistakes by forgetting some important requirements. SOTIP has been tested in a few large procurements in Sweden and in the Netherlands. It was also adopted by the European Commission and it is used as a recommendation under the name EOTIP (European Open Telecommunication systems Interconnection Profile). [17]

\section{Conclusions and further research questions}

Telecommunications are among the most natural candidates for outsourcing for the public sector as it is not a core business and there are several operators that can provide telecommunications services.

The cost reduction is a key driver for many outsourcing decisions. That is the case also for outsourcing of telecommunications. However, it can actually be beneficial to increase investments in telecommunications, and concentrate on reducing the price per service-unit and to use telecommunications as a tool for business development. Such a strategy is due to the general importance of telecommunications for further development of any organization's activities, the relatively low share that telecommunication costs constitute of an organizations' overall budget and the rapid technical development. It means that the outsourcing decision has not only immediate but also far-reaching consequences for the outsourcing organization for a long time in the future.
There are a number of further research questions. First, it would be informative to analyze actual public and private cases of outsourcing of telecommunications using SOTIP model. Second, it would be of great value to find out if there are any differences between private and public sectors regarding outsourcing of telecommunications. Third, SOTIP model has been used and validated in a few big public procurements. Outsourcing of telecom services was a part of these procurements. It would be of interest to investigate some years after the outsourcing decision and contract signing how well the SOTIP model functioned and in which way it could be improved. Fourth, it would be useful to find out if there are any differences in implementation and usage as well as results of outsourcing between different public authorities and in different countries. Fifth, it would be of interest to compare the cases of outsourcing of telecom services that used SOTIP model and those that did not use it.

\section{References}

[1] Arnold, Ulli (2000) - New dimensions of outsourcing: a combination of transaction cost economics and the core competencies concept, European Journal of Purchasing \& Supply Management 6, p.24

[2] Baily, Peter, Farmer, David, Jessop, David \& Jones, David (1998) - Purchasing principles \& management, Financial Times pitman Publishing, 8th edition, pp 66, 283-284, 289-290

[3] Bolkestein, Frits (2004) - Public-Private Partnerships and concessions: the players have the floor, Brussels, speech 17.05.2004

[4] Cheon, Myun J., Grover, Varun \& Teng, James T.C. (1995) Theoretical perspectives on the outsourcing of information systems, Journal of information Technology (1995) 10, pp 209214

[5] Cox, Andrew (1995) - Relational competence and strategic procurement management, European Journal of Purchasing \& Supply Management Vol.2 No.1

[6] de Looff, L A (1996) - IS outsourcing by public sector organisations, IFIP96 p.1-4

[7] Economides, Nicholas (2003) - Competition Policy in Network Industries: An Introduction, Stern School of Business, New York

[8] Ellram, Lisa M. \& Maltz Arnold B. (1995) - The Use of Total Cost of Ownership Concepts to Model the Outsourcing Decision, The International Journal of Logistics Management, Volume 6, Number 2, pp 55,56

[9] Hancox, Martin \& Hachney, Ray (2000) - IT outsourcing: frameworks for conceptualizing practice and perception, Info Systems J (2000) 10, pp 217-219, 221, 223, 225, 227-228, 232 
[10] Javidan, Mansour (1998) - Core Competence: What doesIt Mean in Practice? Long Range Planning, Vol 31, No.1,

Pergamon, Great Britain, p. 60

[11] Karlsson, Magnus (1998) - The Liberalisation of Telecommunications in Sweden Technology and Regime Change from the 1960s to 1993, Linköping University, Department of Technology and Social Change - Tema T

[12] Kern, Thomas, Willcocks, Leslie P. \& van Heck, Eric (2002) - The Winner's Curse in IT Outsourcing: Strategies for Avoiding Relational Trauma, California Management review, vol.44 no. 2 pp 47-51

[13] Kommunikationsdepartementet (1996) - Moderna telekommunikationer åt alla, Ds 1996:39, Sweden

[14] Kraljic, P. (1983) - Purchasing must become supply management, Harvard Business review, September-October, pp $86-94$

[15] Lindskog, Helena (1996) - From reducing cost of telecommunication to applying telecomms as a tool for business process reengineering - an initiative from the Swedish government administration, paper, ITS eleventh biennial conference, Seville, Spain

[16] Lindskog, Helena (2004) - The Telecommunications Market in Sweden from monopoly to competition, paper presented at ABR conference, San Juan, Puerto Rico, March, 2004

[17] Lindskog, Helena (2004) - How can the private sector benefit from the public sector's e-procurement experiences?, The Internet Society: Advances in learning, Commerce and Security (K.Morgan \& J.M.Spector - editors), WITPress, 2004

[18] Post- och telestyrelsen (2003) - I backspegeln, Erfarenheter av tio år med telelagen, PTS-ER-2003:5, Sweden

[19] Statskontoret (1998) - SOTIP Updated, Stockholm, Sweden

[20] STATTEL-delegationen (1992) - Telefonikostnader inom statsförvaltningen, Stockholm, Sweden

[21] STATTEL-delegationen (1993) - Strategy and Plan of Action for Telephony in Government Administration, Stockholm, Sweden

[22] STATTEL-delegationen (1995) - SOTIP - Swedish government Open Telecommunication systems Interconnection Profile, Version 1, 1995:13, Stockholm, Sweden

[23] STATTEL-delegationen (1995) - Telephony services for the Swedish government administration, Specification of requirements, K:134, 15/95, Stockholm, Sweden

[24] Telecommunications Act (1993:597), 1993, Sweden 